\title{
Research on the Influence of Informatization on Rural Consumption Structure-Based on the Engel's Coefficient Analysis of Rural Families in Chengdu
}

\author{
Yanming $\mathrm{Wu}^{1, \text { a }}$, Bokai Zhang ${ }^{2, \text { b, * }}$ \\ ${ }^{1,2}$ College of Economics, Sichuan Agricultural University, Chengdu, China \\ awuyanmingmo@163.com, brhangbokai@stu.sicau.edu.cn \\ ${ }^{*}$ Corresponding author
}

Keywords: Rural family economy, Consumption structure, Engel's Coefficient, Rural informatization

\begin{abstract}
The 19th National Congress regarded how to deal with the three rural issues as important tasks for the work of the whole party. The rural informatization construction provides a new way to coordinate urban and rural development, and conduct in-depth study of the three rural issues. The researchers conducted a random sample survey of Chengdu, which is representative of the development of the southwest region. The researchers randomly selected various regions of Chengdu to conduct surveys. Firstly, the factorization index was reduced by factor analysis, and then the OLS regression model was constructed by using Engel's Coefficient as the dependent variable with the comprehensive informationization index as the independent variable. Studies have shown that a more complete information construction has a significant positive impact on the Engel's Coefficient of rural households. In addition, the higher the level of informatization, the higher the household income. Finally, based on the results of data analysis and field research, the following recommendations were made. The government should implement price subsidies for televisions, computers, mobile phones, etc., and increase the number of households that hold these information products. Besides, the application of advanced agricultural technology should be promoted and rural information construction should continue to be promoted.
\end{abstract}

\section{Introduction}

Since the rural revitalization strategy, all cities across the country have responded positively and implemented them in action. In order to promote the rural revitalization strategy, Chengdu has accelerated the construction of information technology and made numerous reforms to narrow the digital divide in recent years. All districts and counties in Chengdu have strengthened cooperation, including the establishment of the Agricultural Information Society, regular organization of relevant agricultural experts to conduct regular training for farmers, promotion of Internet e-commerce and other measures to provide farmers with corresponding information, logistics resources, funding, etc. The government hopes to promote the development of rural informatization in Chengdu, gradually increase farmers' incomes and profoundly change the rural household consumption structure through these measures.

However, at present, whether the rural informatization construction really promotes the local rural income increase is currently a major controversy in the academic community. On the one hand, some scholars believe that rural informatization can promote the income of rural households. Xu Zhuqing and Zheng Fengtian conducted an empirical analysis of the survey data of Hainan Province through the PSM method, and believed that the farmers who use the "Nongxintong" have the ability to obtain information and can obtain more bargaining chips for price negotiations [1]. Sun Chu based on the data of 270 rural households in Harbin, concluded that agricultural information technology services can affect the transformation of traditional agriculture, and gradually adjust the agricultural industrial structure to increase the income of farmers [2]. Wang Yan (2011) based on data from Lichuan City, Hubei Enshi Autonomous Prefecture, believes that informationization has a positive correlation with farmers' income [3]. On the other hand, some scholars believe that the rural informatization construction does not match the current situation of rural development, so it is impossible to increase 
the income of rural households, such as Zhang Leilei[4]. Some scholars believe that the gap in mobile Internet knowledge is widened due to insufficient rural infrastructure. As a result, informatization can't really make a difference. For example, Tan Yanzhi (2017) has studied that informatization only brings about a $21 \%$ increase in the salary of urban residents, but it has no significant impact on rural families, and it also shows the city from the side. There are still huge differences with the level of informatization in rural areas [5].

This paper is different from the previous academics' research on the income of rural households as a variable, but indirectly reflects whether the actual income of rural households is improved through the Engel's Coefficient as a dependent variable. According to Engel's law, the lower the Engel's Coefficient, which means the lower the proportion of food expenditure to total consumer expenditure, the higher the individual income level. Therefore, the income level can be reflected indirectly through the Engel's Coefficient. And this paper is innovative.

\section{Data and methods}

\subsection{Data sources}

The data in this paper is based on a survey conducted by the research team in Chengdu from August 2018 to January 2019. Eight townships were selected through random sampling. Before the investigation, the research team conducted unified training for the researchers, and asked the researchers to conduct random questionnaire surveys by means of household interviews without prior notice to the respondents and the absence of village cadres. The respondents are heads of households or family members who play a decisive role in family affairs. A total of 303 questionnaires were issued and 303 questionnaires were returned. Except for the questionnaires that were judged to be invalid and the questionnaires with more information missing, the team finally received 278 valid questionnaires, and the effective rate of the questionnaire was $91.74 \%$.

\subsection{Variable setting}

\subsubsection{Dependent variable}

This study mainly explores the impact of informatization on the Engel's Coefficient of rural households. The dependent variable is the Engel's Coefficient of rural households, which is expressed by the 2017 food expenditure/2017 total consumption expenditure.

\subsubsection{Independent variable}

Referring to the existing researches, this study classifies the factors effecting the Engel's Coefficient of rural households into eight information indicators: the number of televisions, the number of mobile phones that can be accessed online, the number of computers, the number of Internet users, the number of people engaged in agricultural product network sales, whether to use new agricultural technology, the approach of getting information and whether the traceability of blockchain can be accepted. Considering many factors effecting household expenditure, the total income of households in 2017 was the control variable when the data was processed.

\subsubsection{Descriptive statistics}

Table 1 Indicator descriptive statistics

\begin{tabular}{ccccccc}
\hline & Index & Calculation method / unit & average & $\begin{array}{c}\text { Standard } \\
\text { deviation }\end{array}$ & min & max \\
\hline & \multicolumn{1}{c}{ Number of televisions } & $\begin{array}{c}\text { Family per capita } \\
\text { (sets/ person) }\end{array}$ & 0.337 & 0.199 & 0 & 1 \\
\cline { 2 - 7 } $\begin{array}{c}\text { Independent } \\
\text { variable }\end{array}$ & $\begin{array}{c}\text { the number of mobile phones } \\
\text { that can be accessed online }\end{array}$ & $\begin{array}{c}\text { Family per capita } \\
\text { (sets/ person) }\end{array}$ & 0.68 & 0.307 & 0 & 2 \\
\cline { 2 - 7 } & the number of computers & $\begin{array}{c}\text { Family per capita } \\
\text { (sets/ person) }\end{array}$ & 0.14 & 0.182 & 0 & 1 \\
\cline { 2 - 7 } & the number of Internet users & (person) & 0.567 & 0.297 & 0 & 1 \\
\hline
\end{tabular}




\begin{tabular}{|c|c|c|c|c|c|c|}
\hline & $\begin{array}{c}\text { the people engaged in } \\
\text { agricultural product network } \\
\text { sales }\end{array}$ & 1 if there is, 0 if not & 0.176 & 0.382 & 0 & 1 \\
\hline & $\begin{array}{l}\text { the approach of getting } \\
\text { information }\end{array}$ & $\begin{array}{l}\text { never getting }=0 \text {, through the } \\
\text { network }=1, \text { the village } \\
\text { popularization }=2, \text { through } \\
\text { friends and family }=3\end{array}$ & 0.568 & 0.904 & 0 & 3 \\
\hline & $\begin{array}{l}\text { whether the traceability of } \\
\text { blockchain can be accepted }\end{array}$ & accepted $=1$, unaccepted $=0$ & 0.651 & 0.478 & 0 & 1 \\
\hline & $\begin{array}{l}\text { whether to use new } \\
\text { agricultural technology }\end{array}$ & $\mathrm{Yes}=1, \mathrm{No}=0$ & 0.417 & 0.494 & 0 & 1 \\
\hline $\begin{array}{l}\text { Control } \\
\text { variable }\end{array}$ & family income & $¥$ & 14844.5 & 16652.7 & 360 & 216000 \\
\hline $\begin{array}{l}\text { Dependent } \\
\text { variable }\end{array}$ & Engel's Coefficient & $\%$ & 0.367 & 0.2 & 0.01 & 0.866 \\
\hline
\end{tabular}

\subsection{Reliability test of the questionnaire}

The reliability test was carried out on multiple indicators involving informationization in the questionnaire. The clone Bach coefficient was 0.662, which was greater than 0.6, indicating that the above questionnaire indicators can be used for academic research.

\section{Empirical analysis}

This section mainly used the ratio of food expenditure to total consumption expenditure, that is, the Engel's Coefficient as the dependent variable, and then reduced the dimension of the informatization index through factor analysis, and took the total income of rural households as a control variable for OLS regression.

\subsection{Dimensionality reduction of informatization indicators through factor analysis}

The informatization index was tested. The value of KMO was 0.621 , which was greater than 0.6 , and the significance of Bartlett's spherical test was 0, indicating that multiple informatization indicators can be reduced by factor analysis.

Table 2 Total variance interpretation

\begin{tabular}{|c|c|c|c|c|c|c|c|c|c|}
\hline \multirow[b]{2}{*}{ component } & \multicolumn{3}{|c|}{ Initial eigenvalue } & \multicolumn{3}{|c|}{$\begin{array}{l}\text { Extracting the sum of squared } \\
\text { loads }\end{array}$} & \multicolumn{3}{|c|}{ Sum of squared rotational loads } \\
\hline & total & $\begin{array}{l}\text { Percenta } \\
\text { ge of } \\
\text { variance }\end{array}$ & $\begin{array}{c}\text { Cumulative } \\
\%\end{array}$ & total & $\begin{array}{l}\text { Percentage } \\
\text { of variance }\end{array}$ & $\begin{array}{c}\text { Cumulative } \\
\%\end{array}$ & Total & $\begin{array}{l}\text { Percentage } \\
\text { of variance }\end{array}$ & $\begin{array}{c}\text { Cumulative } \\
\%\end{array}$ \\
\hline 1 & 2.239 & 27.988 & 27.988 & 2.239 & 27.988 & 27.988 & 1.838 & 22.980 & 22.980 \\
\hline 2 & 1.291 & 16.140 & 44.128 & 1.291 & 16.140 & 44.128 & 1.394 & 17.429 & 40.409 \\
\hline 3 & 1.064 & 13.300 & 57.428 & 1.064 & 13.300 & 57.428 & 1.293 & 16.168 & 56.577 \\
\hline 4 & 1.005 & 12.561 & 69.989 & 1.005 & 12.561 & 69.989 & 1.073 & 13.412 & 69.989 \\
\hline 5 & .781 & 9.768 & 79.757 & & & & & & \\
\hline 6 & .686 & 8.575 & 88.332 & & & & & & \\
\hline 7 & .621 & 7.764 & 96.096 & & & & & & \\
\hline 8 & .312 & 3.904 & 100.000 & & & & & & \\
\hline
\end{tabular}

Note: The extraction method was principal component analysis. 
As seen in Table 2, the cumulative interpretation percentage of ingredient 1 , component 2 , component 3 , and component 4 is about $70 \%$, indicating that these four principal components have strong explanatory power and can represent the indicator of informatization.

Table 3 Component matrix after rotation

\begin{tabular}{ccccc}
\hline \multicolumn{5}{c}{ Rotated matrix component } \\
\hline & 1 & 2 & 3 & 4 \\
\hline Number of televisions & .467 & .158 & -.041 & -.613 \\
\hline $\begin{array}{c}\text { the number of mobile phones that } \\
\text { can be accessed online }\end{array}$ & .872 & .013 & .122 & -.058 \\
\hline the number of computers & .254 & .123 & .712 & -.121 \\
\hline $\begin{array}{c}\text { the number of Internet users } \\
\text { the people engaged in agricultural } \\
\text { product network sales }\end{array}$ & .846 & .066 & .185 & .171 \\
\hline $\begin{array}{c}\text { the approaches of getting } \\
\text { information }\end{array}$ & .041 & .024 & .853 & .115 \\
\hline $\begin{array}{c}\text { whether the traceability of } \\
\text { blockchain can be accepted }\end{array}$ & .273 & .189 & -.018 & .170 \\
\hline $\begin{array}{c}\text { whether to use new agricultural } \\
\text { technology }\end{array}$ & .048 & .824 & .090 & .775 \\
\hline
\end{tabular}

Note: The extraction method is the principal component analysis method, and the rotation method is Caesar normalized maximum variance method.

As can be seen from Table 3, the number of mobile phones that can be accessed online and the number of Internet users have a greater interpretation of the component 1; the approaches of getting information and whether to use the new agricultural technology to explain the component 2 is greater; the number of computers and the people engaged in agricultural product network sales have a greater interpretation of component 3 ; the number of televisions and whether the traceability of blockchain can be accepted have a greater interpretation of component 4.

There are two kinds of factor analysis to calculate the weighted index, one is to use the factor load matrix / sqrt (eigenvalue) combined with the variance ratio to calculate the weight, and the other is to directly use the factor score coefficient matrix. Here, we choose the first method, according to Table 2, Table 3, we can calculate the weighted indicators of informationization.

Calculated as follows

$$
\begin{gathered}
\mathrm{F}_{\mathrm{i}}=\mathrm{a}_{\mathrm{ijj}} / \mathrm{b}_{\mathrm{i}} \\
\mathrm{F}=\mathrm{X}_{1} / \mathrm{X}^{*} \mathrm{~F}_{1}+\mathrm{X}_{2} / \mathrm{X}^{*} \mathrm{~F}_{2}+\mathrm{X}_{3} / \mathrm{X}^{*} \mathrm{~F}_{3}+\mathrm{X}_{4} / \mathrm{X}^{*} \mathrm{~F}_{4}
\end{gathered}
$$

\subsection{Fitting with OLS linear regression model}

$$
\mathrm{Yi}=\alpha+\beta \mathrm{s}_{\mathrm{i}}+\varepsilon
$$

Table 4: Hierarchical Regression of Engel's Coefficients by Informatization Weighted Indicators and Income

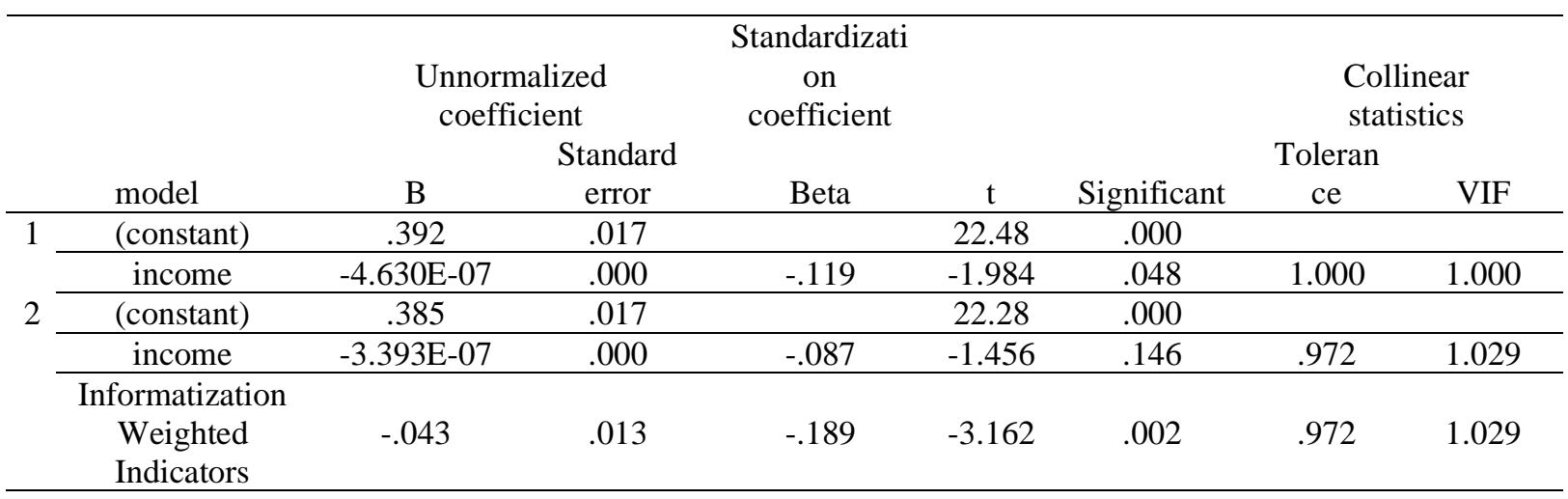

Note: The dependent variable is the Engel's Coefficient of the rural family. 
Result:

$$
\mathrm{Y}_{\mathrm{i}}=0.385-0.43 * \mathrm{~F}
$$

It can be seen from Table 4 that the significance of income to Engel's Coefficient is 0.048, which has a significant effect. According to the informatization weighted index calculated in the first step, linear regression is used to analyze the influence of informatization on the Engel coefficient of rural residents. Taking into account the impact of income levels on food expenditures, the research team used stratified regression analysis to analyze the impact ofl income on the Engel coefficient. Then the research group analyzes the impact of the weighted informationization index on the Engel's Coefficient by controlling the income variable.

As shown in Table 4, the significance of the informatization weighted index is 0.002 , indicating that under the condition of 5\% significance level, informatization significantly affects the Engel's Coefficient of rural residents and is negatively correlated with it. This shows that the higher the level of informatization, the smaller the Engel's Coefficient of rural households, indicating that the living standards of rural residents are higher.

\section{Summary}

Combined with the above research, this paper draws the following conclusions.

First of all, informatization has a significant impact on the Engel's Coefficient of rural residents. That means informatization will reduce people's share of food expenditure, so that residents can obtain more spiritual needs while fully satisfying their survival needs. Therefore, increasing rural informatization construction is an indispensable task for developing rural economy and promoting rural revitalization.

Secondly, this paper can indirectly conclude through research: the rural informatization construction in Chengdu has a significant impact on the income level of residents. It shows that the development of rural informatization in Chengdu promotes the improvement of living standards of rural residents and improves the quality of life. At the same time, it indicates that Chengdu's relevant policies for rural informatization can be used for reference. Therefore, the government should continue to increase the intensity of rural informatization construction and support enterprises or individuals who are willing to develop agricultural product online sales. In addition, the government should also actively expand access to information for rural residents, such as price subsidies for computers. Regular technical training in rural areas is also an indispensable method to promote information construction.

The shortcoming of this paper is that it only studied the influence of informatization on the Engel's Coefficient of rural families, but ignored the influence of informatization on other consumption structures and the internal influences among various consumption structures. The research group considered that food expenditure is the most important component of the consumption structure. Therefore, this study focuses on the Engel's Coefficient. But it is also of practical significance to study the influence of informatization on other consumption structures of rural residents. Later, this part will be studied.

\section{Acknowledgment}

This research was financially supported by and the Sichuan Provincial College Students Innovation Training Program (Item No.201810626101)

\section{References}

[1] Xu Zhuqing, Zheng Fengtian, Chen Jie, "Digital Divide" or "Information Dividend"? Effective Supply of Information and Farmers' Sales Price-_-An Empirical Study from a Microscopic Perspective, Economics (Quarterly), vol.12(04), pp. 1513-1536, 2013. 
[2] Sun Chu, Yang Hui, An Empirical Study on the Impact of Rural Information Technology Services on Farmers' Income-B-Based on the Analysis of Panel Data in Harbin, Journal of Agricultural Mechanization Research, vol.36(10), pp. 58-62+67,2014.

[3] WANG Yan, LI Zhong-bin, MAO Zhong-ming, Study on the Relationship between Rural Informatization and Farmers' Income in Ethnic Areas- - An Empirical Analysis Based on the Survey Results of Lichuan City in Enshi Prefecture, China Population. Resources and Environment, vol.21(S1), pp. 255-258, 2011.

[4] Zhang Leilei, Wang Huan, Li Liantao, Wang Xinzhe, Enlightenment of China's Agricultural Informationization to Promote Farmers' Income Increase in China, Tianjin Agricultural Sciences, vol. 21(10), pp. 54-57,2015.

[5] Tan Yanzhi, Li Yunzhong, Hu Wanjun, Digital Divide or Information Dividend: Research on the Difference of Income Rate of Urban and Rural Revenue from Informatization, Research on Modern Economy, vol.10, pp. 88-95,2017.

[6] He Da, Gu Jiang, The Impact of Internet on Consumption Level and Structure of Rural Residents-_-An Empirical Study of PSM Based on CFPS Data, Rural Economy, vol.10, pp. 51-57, 2018.

[7] Liu Hu,Zhang Jiaping, The Influence of Internet on the Consumption Structure of Rural Residents and Regional Differences, Finance and Economics,vol.04,pp. 80-88,2016.

[8] Xiang Yubing, Internet Development and the Upgrade of Residents' Consumption Structure, Journal of Zhongnan University of Economics and Law, vol.04, pp. 51-60,2018

[9] Tang Caikun, Analysis of the Influence of "Internet + " on the Consumption Economic Structure of Rural Residents, Statistics \& Decision, vol. 34(21), pp. 117-119,2018. 